\title{
Wind and turbulence in the urban boundary layer - analysis from acoustic remote sensing data and fit to analytical relations
}

\author{
Stefan EMEIs*1, KATHRin BAUMANN-STANZER ${ }^{2}$, MARTIN PIRINGER ${ }^{2}$, \\ Margarita Kallistratova ${ }^{3}$, RostislaV Kouznetsov ${ }^{3}$ and VladislaV YushKov ${ }^{3}$ \\ ${ }^{1}$ Institut für Meteorologie und Klimaforschung - Atmosphärische Umweltforschung (IMK-IFU) \\ Forschungszentrum Karlsruhe GmbH, Garmisch-Partenkirchen, Germany \\ ${ }^{2}$ Zentralanstalt für Meteorologie und Geodynamik, Vienna, Austria \\ ${ }^{3}$ Obukhov Institute for Atmospheric Physics, Russian Academy of Sciences, Moscow, Russia
}

(Manuscript received November 30, 2006; in revised form May 7, 2007; accepted May 14, 2007)

\begin{abstract}
Mean seasonal profiles of wind speed, standard deviation of the vertical velocity and turbulence intensity from SODAR measurements in three cities of different size, Moscow, Hanover and Linz, are compared to analytical approximations for the Prandtl and Ekman layer. Typical urban features in the profiles and differences to measurements at rural sites are discussed. Typical urban features are a greater slope in the wind profiles, enhanced turbulence intensities, and a vertical increase in magnitude of the turbulence. The analytical approach proposed by ETLING (2002) for the description of the vertical wind profile in the whole boundary layer is amended in the Prandtl-layer part by a correction function for atmospheric stability. The amended profile description turns out to render the best results for the approximation of urban wind profiles within the lowest $500 \mathrm{~m}$ above ground.

\section{Zusammenfassung}

Mittlere saisonale Profile der Windgeschwindigkeit, Standardabweichung der Vertikalgeschwindigkeit und der Turbulenzintensität aus SODAR-Messungen in drei unterschiedlich großen Städten, Moskau, Hannover und Linz, werden mit analytischen Annäherungen für die Prandtl- und die Ekman Schicht verglichen. Typische Eigenschaften für diese Profile in Städten sind eine stärkere Zunahme des Windgeschwindigkeitsprofils mit der Höhe, höhere Turbulenzintensitäten und die Zunahme der Turbulenz mit der Höhe. Der analytische Ansatz, welcher von ETLING (2002) für die Beschreibung des Windprofils in der gesamten Grenzschicht vorgeschlagen wird, wird in der Prandtl Schicht durch eine Korrekturfunktion zur Berücksichtigung der atmosphärischen Stabilität erweitert. Die erweiterte Profilbeschreibung ermöglicht die beste Annäherung an städtische Windprofile in den untersten 500 m über Grund.
\end{abstract}

\section{Introduction}

Wind and turbulence within the urban boundary layer (UBL) determine the horizontal and vertical dispersion and transport of air pollutants in towns and is thus important for the health of the citizens. Numerous field experiments (for an overview see e.g. GRIMMOND, 2006), numerical studies (see e.g. BATCHVAROVA and GRYNING (2006)) and several wind tunnel studies (COUNIHAN, 1973; FARELL and IVENGAR, 1999; SCHATZMANN and LeITL, 2002) therefore have been conducted to investigate the structure of the UBL. Besides of a better understanding of mixing and transport processes within the UBL, a realistic representation of the flow field within street canyons and above

\footnotetext{
${ }^{*}$ Corresponding author: Stefan Emeis, Institut für Meteorologie und Klimaforschung, Atmosphärische Umweltforschung (IMK-IFU) Forschungszentrum Karlsruhe GmbH, Kreuzeckbahnstr. 19, 82467 Garmisch-Partenkirchen, Germany, e-mail: stefan.emeis@imk.fzk.de
}

the buildings is essential for the application of dispersion models to urban areas (e.g. model simulations for London with ADMS Urban (CERC, 2001)). Detailed urban surface exchange parameterisation schemes have been developed e.g. by MASSON (2000), MARTILLI et al. (2002) and DUPONT and MESTAYER (2006). As continuous wind profile measurements within the urban area are not available in most cases, analytical wind profiles are used in state of the art air pollution modelling to extend the observed wind from e.g. $10 \mathrm{~m}$ above roof top to the entire UBL. Recommendations concerning wind measurements in cities are given by FISHER et al. (2005).

Recent special campaigns like BUBBLE (ROTACH et al., 2005) and DAPPLE (DobRE et al., 2005) performed in European cities as well as other measurements (e.g. CASADIO et al., 1996; DUPONT et al., 1999; Hildebrand and ACKERMANN, 1984; MELLING and List, 1980; UnO et al., 1988, 1992; VENKATRAM et 
al., 2004; FISHER et al., 2005; PIRINGER and JOFFRE, 2005; PIRINGER et al., 2007) show that the vertical structure of the atmospheric boundary layer over towns often deviates from the usual layering over flat homogeneous terrain. This is to be attributed to three typical features of town surfaces: (1) town surfaces have a large roughness with a wide spectrum of different roughness elements, (2) urban areas tend to be warmer than their surroundings due to the increased heat storage at and the reduced evaporation from artificial surfaces, and (3) towns often are isolated islands featuring these special surface properties surrounded by rural terrain so that the flow above them is not in equilibrium with the urban surface.

Following Plate (1995), Roth (2000) and PIRINGER and JOFFRE (2005), the urban boundarylayer (UBL) is usually divided into four layers: The lowest one is the urban canopy layer (UCL) which reaches up to the mean top height of the buildings. The next layer is the wake layer in which the influence of single buildings on the flow is still notable. This wake layer usually extends to about two to five times the average building height. Above these two layers which are often jointly addressed as the urban roughness sub-layer (URL, RotACH, 1999) is the constant flux layer (CFL) or inertial sublayer (IS), over homogeneous terrain usually addressed as surface layer or Prandtl-layer. In the uppermost part of the boundary layer above the $\mathrm{CFL}$, the wind direction turns into the direction of the geostrophic wind (often called Ekman layer).

If a convectively driven boundary layer (CBL) is present, no distinction is made between the CFL or Prandtl-layer and the Ekman layer but they are jointly addressed as mixing layer. The thickness of these layers has so far been investigated over urban surfaces for longer time periods only in Moscow (Pekour and Kallistratova, 1993; Pekour et al., 1993; LOKOSHCHENKO, 2002), in Hanover (EMEIS and TÜRK, 2004) and Toronto for the CBL (MELLING and LIST, 1980).

EMEIS (2004) presents a first evaluation of monthly mean vertical wind profiles and diurnal courses of monthly mean wind speed, of the standard deviation of the vertical velocity $\mathrm{w}$, and turbulence intensity in the URL and CFL derived from SODAR measurements in Hanover for heights up to $225 \mathrm{~m}$ from an extended observation period of 17 months. The main results are that no diurnal variation of the mean wind speed is found in the URL (about $60 \mathrm{~m}$ above ground, about 30 to $40 \mathrm{~m}$ above mean roof level), that the amplitude of the diurnal course of $\sigma_{w}$ and turbulence intensity is large in both layers due to the heating of the urban surface (in spring and summer daytime values are sometimes even more than twice as large than night-time values) and that $\sigma_{w}$ increases with height in the surface layer up to about 300 to $400 \mathrm{~m}$ above ground, especially in summer, indicating an unstable stratification (PANOFSKY et al., 1977). The increase of $\sigma_{w}$ with height is not visible in wind tunnel studies using a realistic model of the surroundings of the Göttinger Straße but confined to neutral thermal stratification of the air (pers. comm. Schatzmann).

Plate (1995) assumes that the same wind profile laws are valid for the CFL and the Ekman layer over towns as applied for flat homogeneous terrain. This assumption has to be scrutinised because the limited spatial extent of a town does not permit an equilibrium flow above the urban area, especially not in higher layers. WIERINGA (1993) postulates an equilibrium flow at height $\mathrm{z}$ above ground if the fetch is homogeneous over about 100 times $z$. The fetch depends on the turbulence intensity because intense mixing accelerates the adaptation to changed surface characteristics. Therefore the fetch should be shorter with very rough surfaces and with unstable thermal stratification. ROTH (2000) limits his assessment of the layers above the URL to the CBL and thus deals only with thermally unstable flows. The intense vertical mixing in the CBL reduces the necessary fetch for an equilibrium flow. ROTH and OKE (1995) therefore postulate fetches more than one order of magnitude less than WIERINGA (1993).

Ground-based remote sensing of wind and turbulence profiles over urban areas from longer measurement campaigns offer the opportunity to learn more about the UBL and to reconsider the wind profile laws used to describe the UBL. In this paper, the wind and turbulence structure in the URL and the CFL (if existent) are investigated in further detail and for heights up to about $500 \mathrm{~m}$ above ground, based on field measurements from Hanover (Germany), Moscow (Russia), and Linz (Austria). The mean wind profiles in the CFL are furthermore approximated with two approaches: (1) a logarithmic wind profile using the Businger-Dyer stability corrections (BUSINGER et al., 1971; DYER, 1974), (2) the wind profile formula for the CFL and Ekman layer suggested by ETLING (2002) which has been modified here to consider also the thermal stratification in the CFL.

\section{Instrumentation and measurement sites}

The presented study is based on SODAR (SOund Detection And Ranging) measurements from the cities Hanover (Germany, about 500.000 inhabitants), Moscow (Russia, about 10 Mio inhabitants), and Linz (Austria, about 200.000 inhabitants). A description of the measurement principle of SODARs is given e.g. by TATARSKiI (1961), MAUGHAN et al. (1982) and BEYRICH (1997).

The METEK DSD3x7 mono-static Doppler SODAR (REITEBUCH and EMEIS, 1998) operated in Hanover 
has three antennas with seven sound transducers each, working at about $1500 \mathrm{~Hz}$. The instrument is optimised for long-range detection up to $1300 \mathrm{~m}$ above ground in ideal conditions without external noise sources. The measurements analysed here have been made from 2001 to 2003. The SODAR site in Hanover was situated in a near-central industrial area close to a railway property away from residential areas. At this site the usual maximum range for wind and turbulence profiles was between 500 and $800 \mathrm{~m}$ depending on the atmospheric conditions as well as on the day of the week. The range was highest on Sundays and public holidays when no shunting of good waggons was made on the nearby railway area. The data are averaged over $30 \mathrm{~min}$ in time and $12.5 \mathrm{~m}$ in the vertical. The measurements were performed in the national research project VALIUM (SCHATZMANN et al., 2006) within the framework programme AFO2000 of the German Ministry of Eduaction and Research BMBF.

Two monostatic LATAN sodars developed at the Obukhov Institute of Atmospheric Physics (IAPh), Russian Academy of Sciences, are continuously operated since April 2005 at two sites: (1) at the IAPh building in downtown Moscow and (2) at the Physical Faculty of Moscow State University (MSU) in the south-west district of Moscow. Additionally, two monthly campaigns with continuous, simultaneous wind measurement downtown of Moscow and at a rural site $45 \mathrm{~km}$ west of Moscow were carried out in October 1993 and in July 2005.

The REMTECH phased array SODAR PA2 operated at Linz is also a mono-static Doppler Sodar with an array of $14 \times 14$ sound transducers, operating at about $1600 \mathrm{~Hz}$. The height range of this instrument depends strongly on ambient noise and on weather conditions. At Linz, data availability was above $90 \%$ up to about $300 \mathrm{~m}$ and then decreased steadily. Data up to $500 \mathrm{~m}$ are evaluated in this study. The data are averaged over $30 \mathrm{~min}$ in time and $20 \mathrm{~m}$ in the vertical; the first layer is in $40 \mathrm{~m}$ above ground. Continuous SODAR data are available from 20 November 2004 to 7 April 2005 measured at a site close to the confluence of the rivers Traun and Danube about $5 \mathrm{~km}$ east of the Austrian city of Linz. Whenever the most frequent westerly to north-westerly winds are prevailing, this site is expected to be within the urban plume, the part of the boundary layer downwind of a city carrying with it the properties of the urban atmosphere (PIRINGER and JOFFRE, 2005). The measurements conducted during these wind directions are therefore interpreted as "urban" wind data, the rest of the data-set as "rural".

\section{Analytical descriptions of wind and turbulence profiles}

In the CFL, a logarithmic wind profile is expected above horizontally homogeneous terrain. For the vertical profile of the mean wind speed with the inverse of the van Kármán constant $1 / \kappa=2.5$ and the stability-dependent correction function $\Psi_{m}\left(z / L_{*}\right)$ (BUSINGER et al., 1971; DYER, 1974) holds:

$$
u(z)=2.5 u_{*}\left(\ln \left(z / z_{0}\right)-\Psi_{m}\left(z / L_{*}\right)\right),
$$

with

$$
\begin{aligned}
& \Psi_{m}\left(z / L_{*}\right)= \\
& \left\{\begin{array}{ccc}
\ln \left(\frac{\left(1+x^{2}\right)}{2}\left(\frac{(1+x)}{2}\right)^{2}\right) & \text { for } & z / L_{*}<0 \\
-2 \operatorname{arctg}(x)+\frac{\pi}{2} & \text { for } \quad 0<z / L_{*} \leq 0.5 \\
-a z / L_{*} & \text { for } 0.5 \leq z / L_{*} \leq 7 \\
A z / L_{*}+B\left(z / L_{*}-C / D\right) &
\end{array}\right.
\end{aligned}
$$

and $x=\left(1-b z / L_{*}\right)^{1 / 4} . L_{*}$ is the Monin-Obukhov length. Following HÖGSTRÖM (1988) $a$ is set to 5 and $b$ is set to 16 . In the third equation for stronger stable conditions (LANGE and Focken, 2006) is $A=1, B=2 / 3$, $C=5$ and $D=0,35$. For the variance $\sigma_{w}$ of the vertical wind component in neutral and slightly stable conditions the following relation should hold (STULL, 1988):

$$
\sigma_{w}(z)=1.3 u_{*}
$$

and thus for the turbulence intensity by dividing (3.3) by (3.1):

$$
\frac{\sigma_{w}(z)}{u(z)}=\frac{0.52}{\ln \left(z / z_{0}\right)-\Psi_{m}\left(z / L_{*}\right)}
$$

which is similar to the relation found by WIERINGA (1973) for the longitudinal variance under neutral stratification. For the variance of the vertical velocity component $\sigma_{w}$ under unstable conditions PANOFSKY et al. (1977) propose

$$
\sigma_{w}=1.3 u_{*}\left(1-3 z / L_{*}\right)^{1 / 3} .
$$

and thus for the turbulence intensity by dividing (3.5) by (3.1):

$$
\frac{\sigma_{w}(z)}{u(z)}=\frac{0.52\left(1-3 z / L_{*}\right)^{1 / 3}}{\ln \left(z / z_{0}\right)-\Psi_{m}\left(z / L_{*}\right)}
$$

This implies an increase of $\sigma_{w}$ with height in the Prandtl layer under unstable thermal conditions. 
For the Ekman layer, the vertical wind speed profile depends on the geostrophic wind speed $u_{g}$ and the (vertically constant) turbulent exchange coefficient for momentum $\mathrm{K}_{M}$ as formulated in the equations for the Ekman spiral:

$$
u(z)=u_{g}(1-2 \exp (-\gamma z) \cos (\gamma z)+\exp (-2 \gamma z))^{1 / 2}
$$

with $\gamma^{2}=f\left(2 \mathrm{~K}_{M}\right)$ and the Coriolis parameter f. For thermally unstable situations when $\mathrm{K}_{M}$ becomes large, (3.7) can be simplified following EMEIS (2001) because the cosine function approaches unity:

$$
u(z)=u_{g}(1-\exp (-\gamma z))
$$

The main difference between (3.7) and (3.8) is that in (3.7) $\mathrm{u}(\mathrm{z})$ oscillates around $u_{g}$ when approaching $u_{g}$ whereas $\mathrm{u}(\mathrm{z})$ approaches $u_{g}$ monotonically in (3.8). The Ekman layer laws (3.7) and (3.8) suffer from the assumption of a vertically constant exchange coefficient and cannot be extended towards the ground. Therefore ETLING (2002) proposes a two-layer model. In his model the exchange coefficient is assumed to increase linearly with height $\left(=\kappa u_{*} \mathrm{z}\right)$ below the height of the Prandtl layer (CFL) $\mathrm{z}_{p}$ and to be constant $\left(=\kappa u_{*}\right.$ $\mathrm{z}_{p}$ ) above. Etling's approach is followed here with the application of one amendment: the correction function $\Psi_{m}\left(z / L_{*}\right)$ for the thermal stratification of the Prandtl layer is applied below the height $z_{p}$. This leads to the following vertical profile of the mean wind speed:

$$
\begin{aligned}
& u(z)= \\
& \left\{\begin{array}{cc}
\frac{u_{*}}{\kappa}\left(\ln \left(z / z_{0}\right)-\Psi_{m}\left(z / L_{*}\right)\right) & \text { for } \quad z<z_{p} \\
u_{g}\left(-\sin \alpha_{0}+\cos \alpha_{0}\right) & \text { for } \quad z=z_{p} \\
u_{g}\left[1-2 \sqrt{2} \exp \left(-\gamma\left(z-z_{0}\right)\right)\right. & \\
\cdot \sin \alpha_{0} \cos \left(\gamma\left(z-z_{0}\right)+\frac{\pi}{4}-\alpha_{0}\right) \\
\left.+2 \exp \left(-2 \gamma\left(z-z_{0}\right)\right) \sin ^{2} \alpha_{0}\right]^{1 / 2}
\end{array} \quad \text { for } \quad z>z_{p}\right.
\end{aligned}
$$

(3.9) depends on the following six parameters: the surface roughness $z_{0}$, the geostrophic wind speed $u_{g}$, the height of the Prandtl layer $z_{p}$, the friction velocity $u_{*}$, the Monin-Obukhov length $L_{*}$, and the angle between the surface wind and the geostrophic wind $\alpha_{0}$. The two variables $z_{0}$ and $u_{g}$ are external parameters, the other four of them are internal parameters and vary according to the thermal stratification of the layer. If fixed values for $z_{p}$ - as done by ETLING (2002) - and for $L_{*}$ are chosen, two further equations in addition to (3.9) are needed to determine $u_{*}$ and $\alpha_{0}$ accordingly. These equations are generated here from the physical requirement that both the wind speed as well as the wind shear are continuous in the height $z=z_{p}$. Equating the first two equations of the wind profile equation (3.9) for $z=z_{p}$ gives:

$$
u_{*}=\frac{\kappa u_{g}\left(-\sin \alpha_{0}+\cos \alpha_{0}\right)}{\ln \left(z_{p} / z_{0}\right)-\Psi_{m}\left(z_{p} / L_{*}\right)}
$$

and from equating the respective shear equations in the same height $z=z_{p}$ we get:

$$
u_{*}=\frac{2\left|u_{g}\right| \gamma \kappa z_{p} \sin \alpha_{0}}{\varphi\left(z_{p} / L_{*}\right)}
$$

with the correction function for thermal stratification (using HÖGSTRÖM's (1988) values for the constants) $\varphi\left(z / L_{*}\right)$ :

$$
\varphi\left(z / L_{*}\right)=\left\{\begin{array}{ccc}
\left(1+16 z / L_{*}\right)^{-1 / 4} & \text { for } & z / L_{*}<0 \\
1 & \text { for } & 0<z / L_{*} \leq 0.5 \\
1+5 z / L_{*} & \text { for } & z / L_{*}>0.5
\end{array}\right.
$$

Equating now the right hand sides of (3.10) and (3.11) yields the desired relation for $\alpha_{0}$ :

$$
\alpha_{0}=\operatorname{arctg} \frac{1}{1+\frac{2 \gamma_{p}}{\varphi\left(z_{p} / L_{*}\right)}\left(\ln \left(z_{p} / z_{0}\right)-\Psi_{m}\left(z_{p} / L_{*}\right)\right)}
$$

(3.13) still depends on $u_{*}$ via $\gamma$ :

$$
\gamma=\sqrt{\frac{f}{2 \kappa u_{*} z_{p}}}
$$

thus $u_{*}$ has to be determined iteratively starting with a first guess for $u_{*}$ in (3.14), subsequently computing $\alpha_{0}$ from (3.13), and then re-computing $u_{*}$ from (3.10) or (3.11). The equation (21.50) in ETLING (2002) is not appropriate to determine $u_{*}$ and from $z_{p}, z_{0}$, and $u_{g}$.

A shortcoming of equations (3.9) to (3.14) is that thermal layering in the Ekman layer is still not considered. Therefore the yielded values for the height of the Prandtl layer and the friction velocity are not fully satisfying but they are better than in the original formulation of ETLING (2002) without considering the thermal layering in the Prandtl layer. Even more complex expressions for the vertical profile of the exchange coefficient $\mathrm{K}_{M}$ lead to systems of equations which no longer can be solved analytically.

We will analyse the results from the sodar measurements given in the following chapter whether the right choice of $z_{p}, u_{*}, L_{*}$ and $\alpha_{0}$ will lead to a meaningful application of the wind profile laws (3.1) and (3.9).

\section{Results}

\subsection{Mean urban wind profiles}

Mean monthly wind profiles observed in Hanover in August and November 2002 and in February and April 

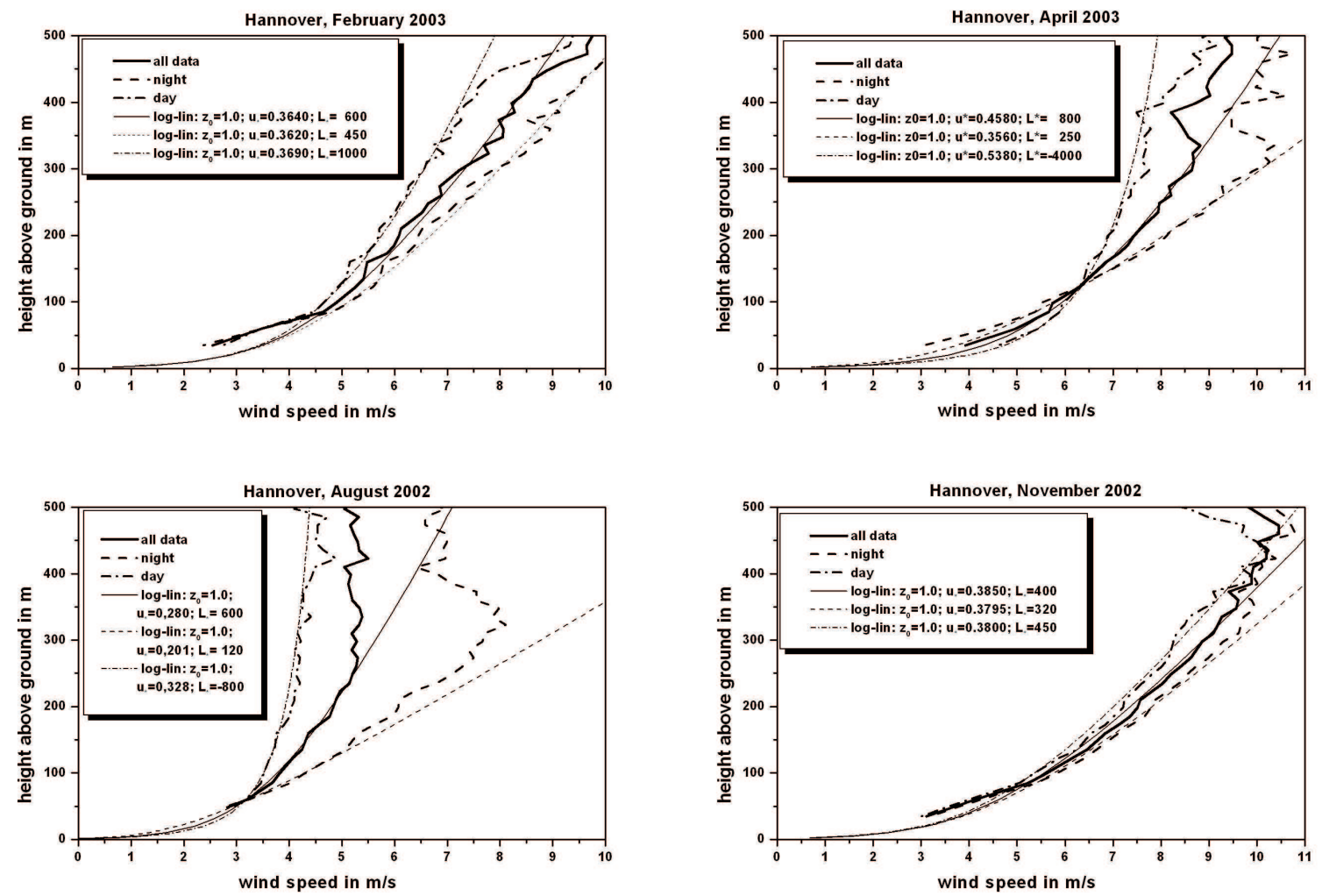

Figure 1: Mean monthly wind profiles for day-time and night-time in Hanover and approximations of these profiles by stability-dependent logarithmic wind profiles from eq. (3.1).
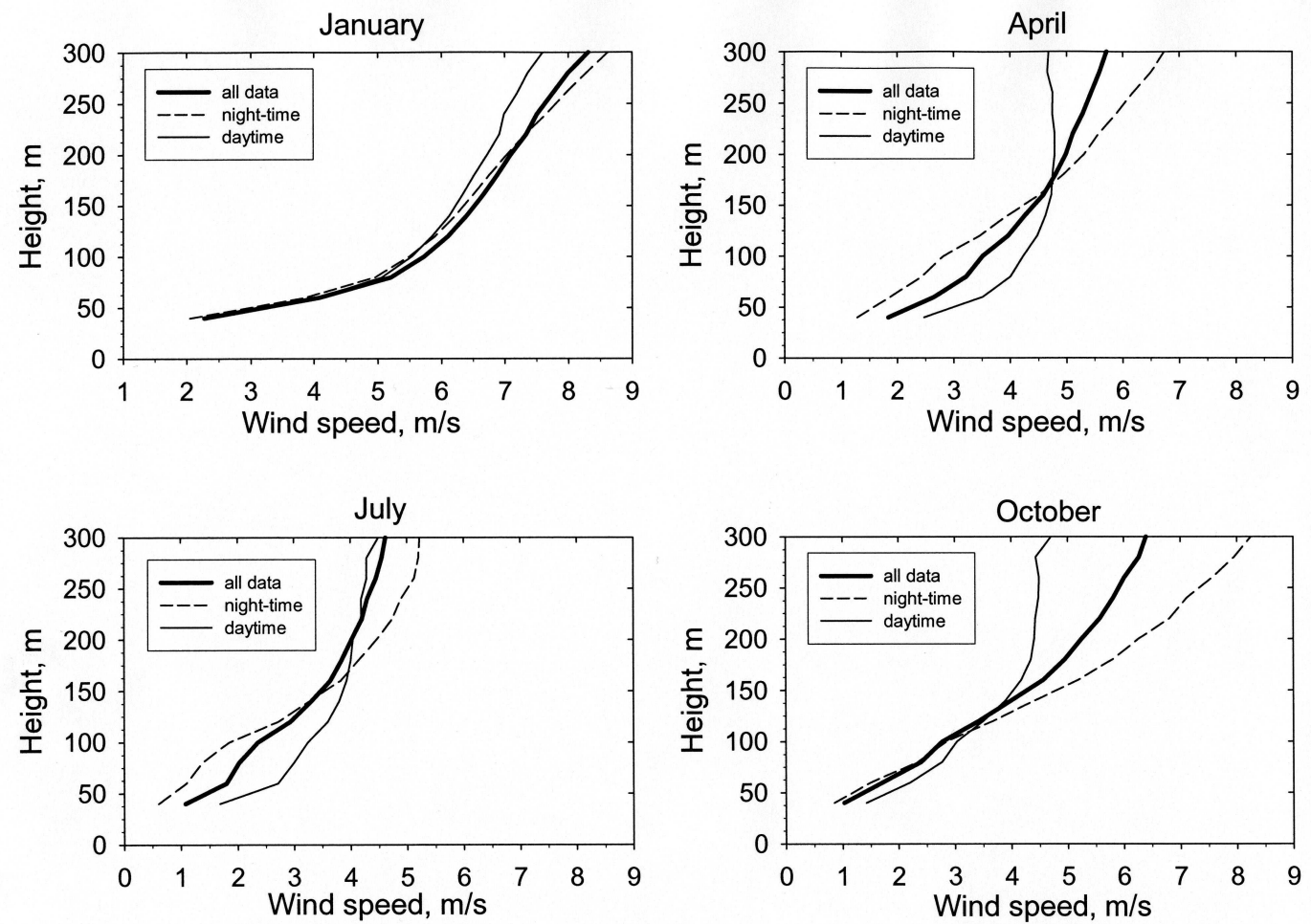

Figure 2: . Mean monthly wind profiles for day-time and night-time in January 2006, April 2005, July 2005 and October 2005 in Moscow. The height range is limited to $300 \mathrm{~m}$. 


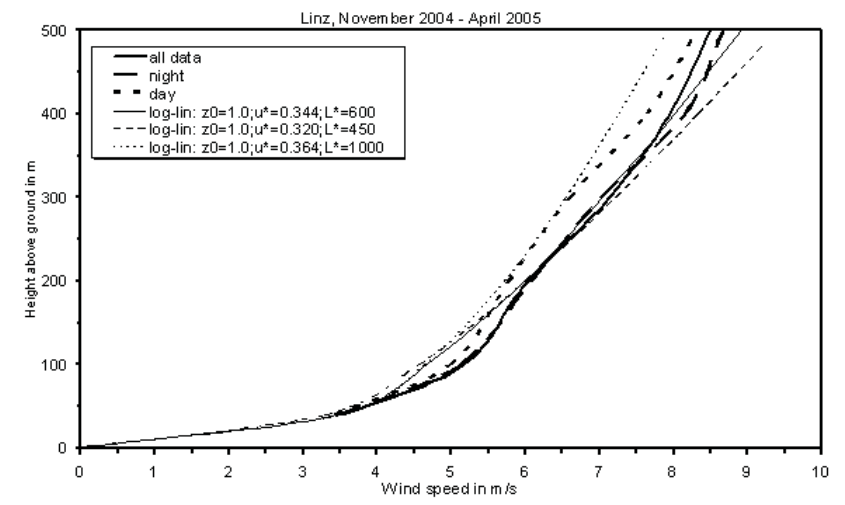

Figure 3: Mean winter wind speed profiles for day and night-time in Linz and approximations of these profiles by stability-dependent logarithmic wind profiles from eq. (3.1).

2003 together with stability-dependent logarithmic wind profiles (Eq. (3.1)) are shown in Fig. 1. These months have been chosen as representative for the four seasons. Nocturnal wind speeds are on average higher than daytime wind speeds in all cases except in April 2003 where the mean wind speeds during day-time below $125 \mathrm{~m}$ above ground occurred to be higher than the night-time averages. The monthly means are computed from 30 min-mean profiles which are complete up to at least 210 $\mathrm{m}$. Above this height the data availability decreases and is about $20 \%$ at $500 \mathrm{~m}$ height. The standard deviation of the wind speed values used for the calculation of the means depends on the season and slightly on the height above ground. It is lowest in November with about $30 \%$ in all heights and largest in August with nearly $50 \%$ in lower heights and roughly $60 \%$ in upper heights.

In autumn and winter the differences between the daytime and the night-time wind profiles are rather small, i.e. the mean stratification of the air is always quite stable $\left(L_{*}=450 \mathrm{~m}\right.$ and $1000 \mathrm{~m}$ at daytime and $320 \mathrm{~m}$ and $450 \mathrm{~m}$ at night, respectively have been used in the fit with eq. (3.1) here). In spring and summer the daytime profiles are distinctively coined by the unstable thermal stratification of the air. $L_{*}$ in the fit with the stability-dependent logarithmic wind profile (3.1) therefore is $-4000 \mathrm{~m}$ and $-800 \mathrm{~m}$ at daytime and $250 \mathrm{~m}$ and $120 \mathrm{~m}$ at night, respectively. The night-time profiles in these two seasons show that low-level-jets with a wind maximum at 300 to $350 \mathrm{~m}$ above ground are frequently observed in the urban area of Hanover. In all fits the roughness length was set to $z_{0}=1 \mathrm{~m}$. $u_{*}$ is varying between $0.201 \mathrm{~m} / \mathrm{s}$ for the night-time profile in August and $0.538 \mathrm{~m} / \mathrm{s}$ for the daytime profile in April. In autumn and winter, the observed average wind profiles within the lowest $500 \mathrm{~m}$ above ground are relatively well represented by the logarithmic wind profile. In spring, the analytic and the mean observed wind profiles agree up to $350 \mathrm{~m}$ above ground, in summer up to $250 \mathrm{~m}$ above

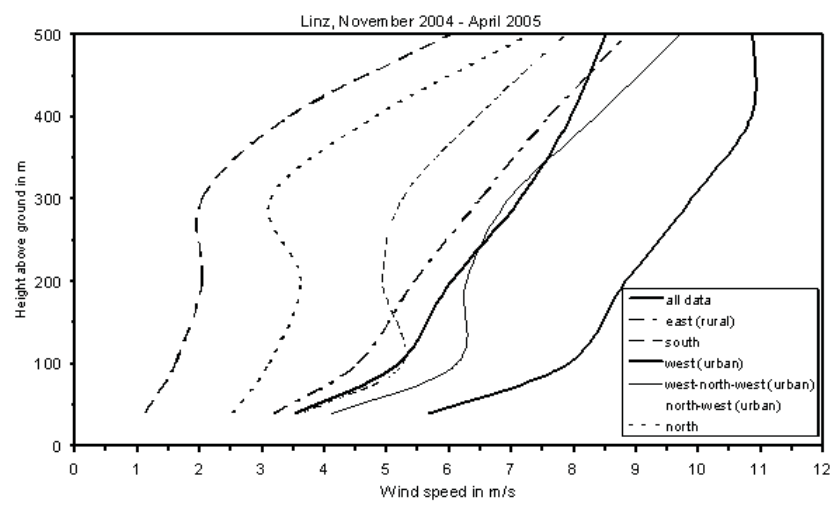

Figure 4: Mean winter wind speed profiles for selected wind directions (urban and non-urban fetch) in Linz.

ground, while the observed wind speeds are on average 1 to $2 \mathrm{~m} / \mathrm{s}$ lower than expected according to the logarithmic wind profiles at higher levels.

Mean monthly wind profiles for day-time and nighttime observed in Moscow in January, April, July and October are depicted in Fig. 2. The seasonal results can be compared to those from the measurements in Hanover (Fig. 1). Please note that the height scales differ between Fig. 1 and Fig. 2. The seasonal differences of the wind profiles observed in Moscow are very similar to those found in Hanover: Day and night-time wind profiles within the lowest $100 \mathrm{~m}$ are similar in autumn and winter. In spring and summer, up to about $150 \mathrm{~m}$, daytime wind speeds are on average 1 to $2 \mathrm{~m} / \mathrm{s}$ higher than at night. Above $150 \mathrm{~m}$, the mean nocturnal wind speeds are always higher than those at day-time. The strong increase of wind speed within the lowest $100 \mathrm{~m}$ shown in Figs. 1 and 2 is typical for urban areas.

Seasonal mean wind speed profiles for wintertime observed in Linz at day- and night-time are shown in Fig. 3. As observed in wintertime in Hanover and Moscow, the average day and night-time wind speeds at Linz are similar below $100 \mathrm{~m}$ above ground and daytime wind speeds are lower than those at night above. The fit with the logarithmic wind profile (3.1) is best with $L_{*}=1000 \mathrm{~m}$ during daytime and $600 \mathrm{~m}$ in the night. As for Hanover a roughness length of $z_{0}=1 \mathrm{~m}$ has been chosen. The friction velocity $u_{*}$ for this winter season in Linz is $0.32 \mathrm{~m} / \mathrm{s}$ at nighttime and $0.36 \mathrm{~m} / \mathrm{s}$ at daytime which is very close to the February 2003 value for Hanover ( $u_{*}=0.36$ at day and night).

\subsection{Comparison of mean urban wind profiles to non-urban wind profiles}

Urban and hilly areas in general have a larger surface roughness than flat rural terrain. Wind speeds are therefore increasing considerably with height for several hun- 

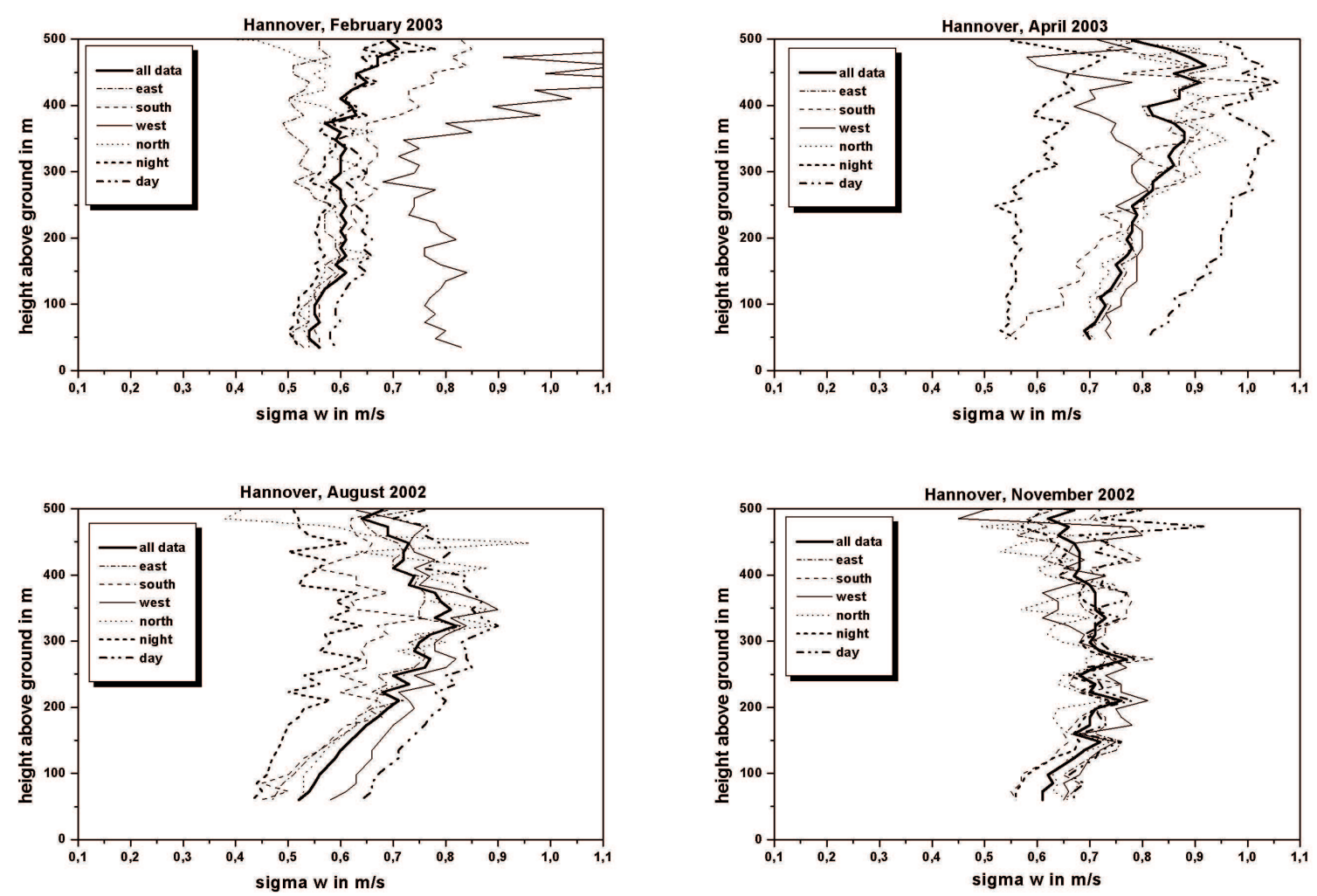

Figure 5: Mean monthly profiles of the variance of the vertical velocity component $\left(\sigma_{w}\right)$ in dependence of the main wind direction and for day-time and night-time in Hanover.

dreds of meters at these sites. Over the smooth rural areas this increase is confined to a shallower layer.

Seasonal mean wind speed profiles for wintertime observed in Linz in dependence of the wind direction are shown in Fig. 4. The separation according to wind directions was chosen in order to investigate whether the city of Linz exerts an urban influence on the wind profiles at the SODAR site downwind of the city. This is anticipated for westerly to north-westerly winds. Northerly winds at the SODAR site are probably influenced by drainage flows from the hills north and north-east of the site; there is also the village of Steyregg situated $1.5 \mathrm{~km}$ north of the site. Another built-up but flat area is found about $1.5 \mathrm{~km}$ south of the site. With easterly winds, the fetch is predominantly rural along the river Danube up to a distance of more than $3 \mathrm{~km}$.

The mean wind speed profiles in Fig. 4 show large differences between wind profiles observed with strong westerlies (between 6 and $11 \mathrm{~m} / \mathrm{s}$ with increasing height) and those observed with weak northerly and southerly flow. The latter show no strong variation in wind speed up to heights of about $300 \mathrm{~m}$; for northerly winds, this is due to the shadowing effects of the aforementioned hills at the northern edge of the Linz basin. The terrain is also steepening towards south, but to a much lesser extent.

The average wind profiles for westerly to northwesterly winds having crossed the urban area show the strongest increase in wind speed between 40 and 100 $\mathrm{m}$ above ground; this is in line with the assumption at the beginning of this section that, due to the increased surface roughness, wind speeds increase stronger with height than over rural terrain. A wind speed maximum is found on average at $100 \mathrm{~m}$ height when westnorth-westerly or north-westerly winds are prevailing. This maximum is also observed in other urban areas by Piringer and BAUMANN (1999), DRAXLER (1986) and BALLING and CERVENY (1987): due to the increased vertical mixing above the urban area, the lowlevel air flow is destabilized and accelerated while crossing the warmer city centre.

\subsection{Mean urban turbulence profiles}

Mean monthly profiles of variances of the vertical velocity component $\left(\sigma_{w}\right)$ in Hanover separated for day and night and for four wind direction sectors are depicted in Fig. 5 for the same months as in Figure 1.

Fig. 5 shows increasing values of $\sigma_{w}$ within the lower few hundred meters of the urban boundary layer in spring and most pronounced in summer, reaching up to about $350 \mathrm{~m}$ above ground. The daytime increase can be explained by unstable stratification (see eq. (3.5). The considerable increase of the night-time $\sigma_{w}$ with height is in the lower $100 \mathrm{~m}$ also due to unstable stratification but above this height probably related to the formation 

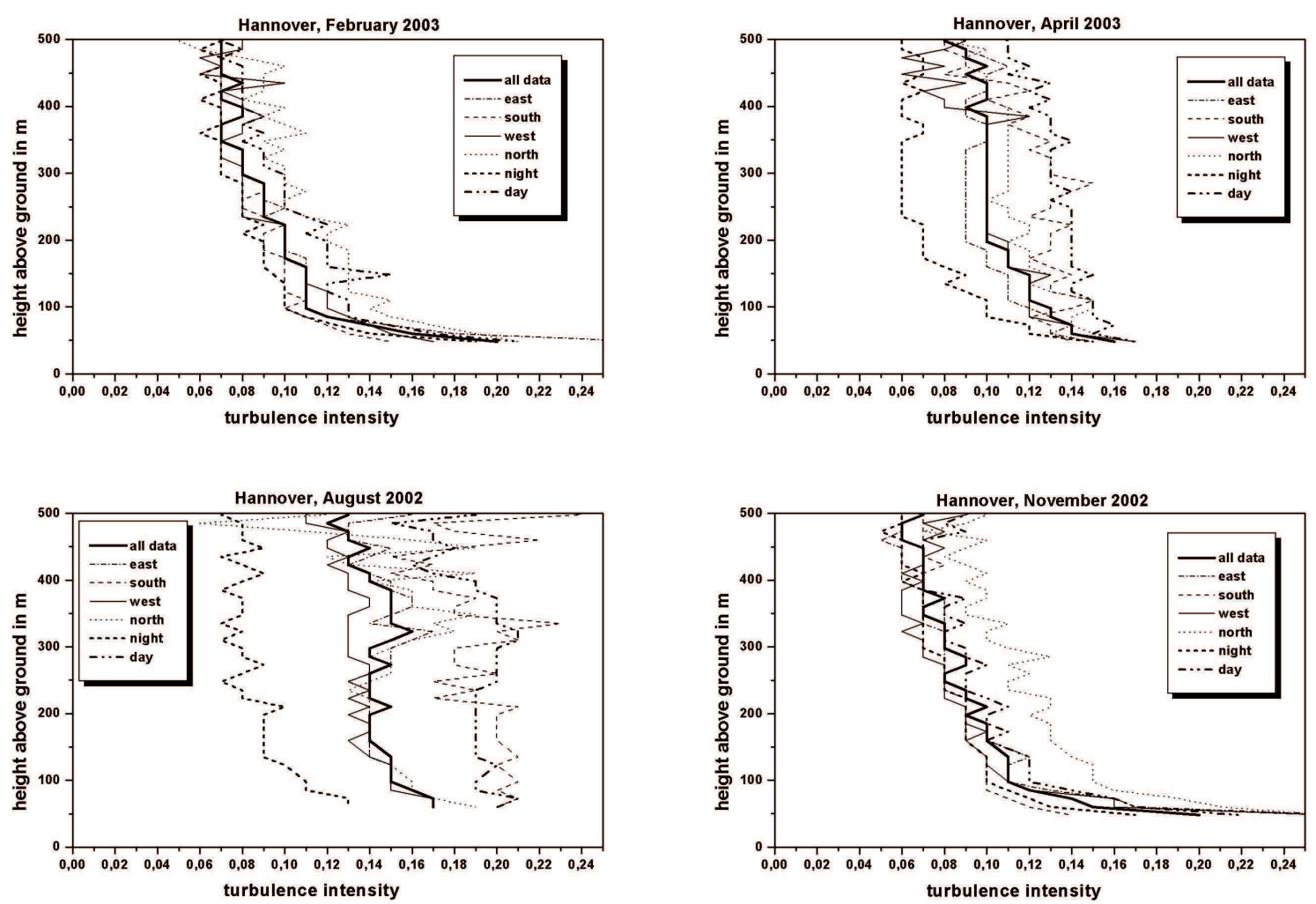

Figure 6: Shows monthly mean profiles of the vertical component of the turbulence intensity observed in Hanover, i.e. $\sigma_{w}$ divided by the average horizontal wind speed. This quantity therefore inversely depends on the mean wind speed.
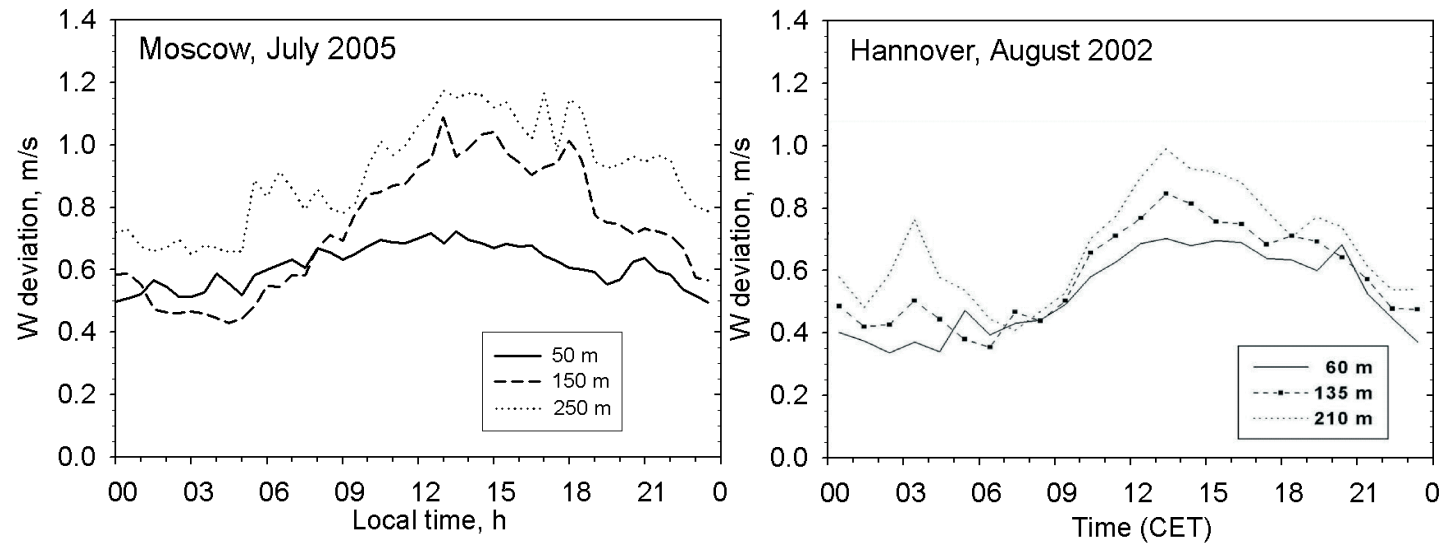

Figure 7: Diurnal variations of the variance of the vertical velocity component $\left(\sigma_{w}\right)$ in summer in Moscow (left) and in Hannover (right).

of nocturnal low-level jets (see the upper right and especially the lower left frame in Figure 1). The maximum of $\sigma_{w}$ is in the same height as the core of the low-level jet. The $\sigma_{w}$ values near the ground are a little bit higher than expected from (3.3) and (3.5). According to these relations and using the $u_{*}$ values used for fitting in Fig. 1 the $\sigma_{w}$ values should range between about $0.3 \mathrm{~m} / \mathrm{s}$ for the night-time variance in August and about $0.7 \mathrm{~m} / \mathrm{s}$ for the daytime variance in April.

The differences between daytime and night-time $\sigma_{w}$ profiles are small in winter and autumn, although the winter profiles show a large dependence of the synoptic wind direction. In wintertime, the largest values of $\sigma_{w}$ occur with usually stronger westerly winds. Night-time and daytime profiles differ most in spring and summertime. In these seasons, the differences between the mean day-time and night-time profiles are much larger than the differences between the mean profiles for different wind directions.

Fig. 6 shows monthly mean profiles of the vertical component of the turbulence intensity observed in Hanover, i.e. $\sigma_{w}$ divided by the average horizontal wind speed. This quantity therefore inversely depends on the mean wind speed. 


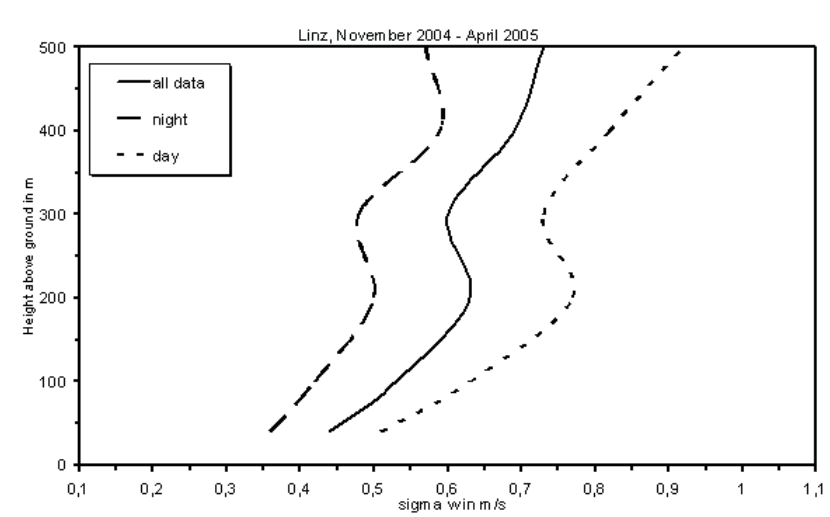

Figure 8: Mean winter profiles of the variance of the vertical velocity component $\left(\sigma_{w}\right)$ for day-time and night-time in Linz.

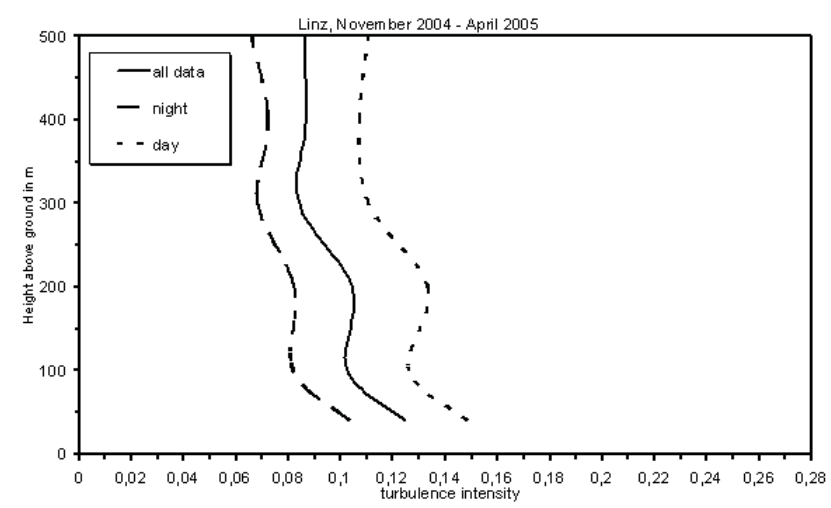

Figure 9: Mean winter profiles of the vertical component of the turbulence intensity for day-time and night-time in Linz.

Turbulence intensity is highest in summer and spring. In these two seasons, the daytime values are twice as high as the night-time values. At daytime, turbulence intensity profiles in spring and summer are more or less constant with height up to 300 to $400 \mathrm{~m}$ above ground. In autumn, winter, and generally at night-time, the profiles show a strong decrease of the turbulence intensity with height within the lower 150 to $200 \mathrm{~m}$ in accordance with eqs. (3.4) and (3.6).

The diurnal course of the variance of the vertical velocity component in summertime is found to be quite similar in Hanover and Moscow. Nevertheless, Fig. 7 indicates that the overall level of $\sigma_{w}$ is somewhat larger in the much larger city of Moscow than in the smaller city of Hanover although the mean wind speeds in Moscow in July 2005 have been even lower than in Hanover in August 2002. Both plots show that $\sigma_{w}$ increases with height at daytime and nighttime in summer in accordance with the profiles shown in the lower left frame of Figure 5.

Seasonal mean $\sigma_{w}$ profiles for wintertime observed in Linz at day- and nighttime and in dependence of the wind direction are shown in Fig. 8 and the mean turbulence intensity profiles in Fig. 9. As mentioned in sec-

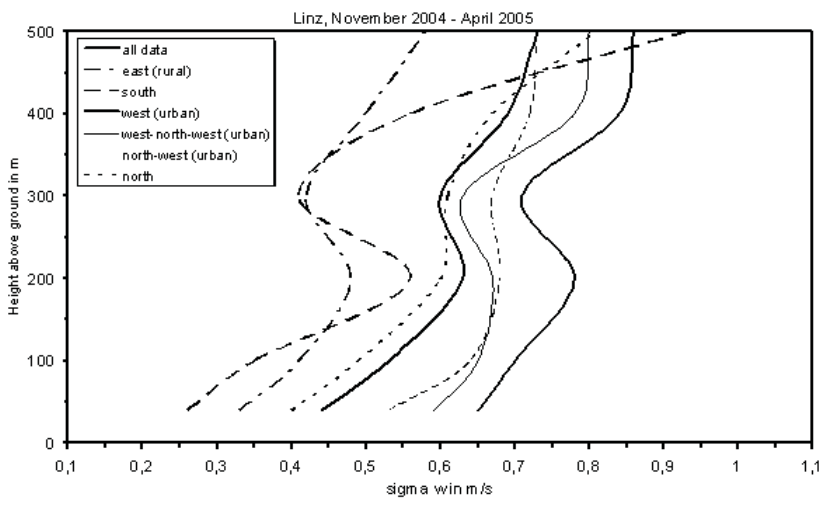

Figure 10: Same as Fig. 8 but different wind direction

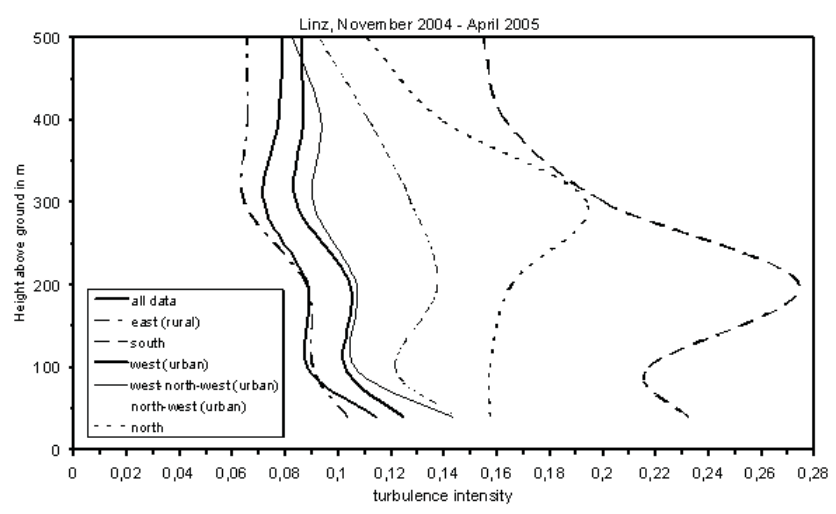

Figure 11: Same as Fig. 9 but different wind direction.

tion 2, the measurement period in Linz covers mainly the winter months. The average $\sigma_{w}$ profiles (Fig. 8) generally show an increase with height. The range is between 0.3 and $0.5 \mathrm{~m} / \mathrm{s}$ near ground and about 0.5 to 0.9 $\mathrm{m} / \mathrm{s}$ at $500 \mathrm{~m}$. The near-ground values of $\sigma_{w}$ in Linz fit quite well to the relations (3.3) and (3.5) from which $\sigma_{w}$ $=0.44$ could be expected using $u_{*}=0.34$ from Fig. 3 . As expected and also found in the other cities, nocturnal $\sigma_{w}$ values are on average lower than daytime values.

The turbulence intensity values in Linz range from below 0.1 to near 0.16 (Fig. 9) and are thus smaller than those observed in Hanover. The average daytime turbulence intensity is about 1.5 times larger than that at night-time.

\subsection{Comparison of monthly mean urban turbulence to non-urban turbulence}

Diurnal variations of the variance of the vertical velocity component $\left(\sigma_{w}\right)$ in Hanover have already been compared in EMEIS (2004) with those from the nonurban site in Fürstenfeldbruck west of Munich (Germany). Due to the higher surface roughness the friction velocity is higher over urban areas. Therefore, according to (3.3) and (3.5) higher variances of the vertical velocity component have been found at urban areas, both at night-time and at daytime. Also the diurnal variations of 

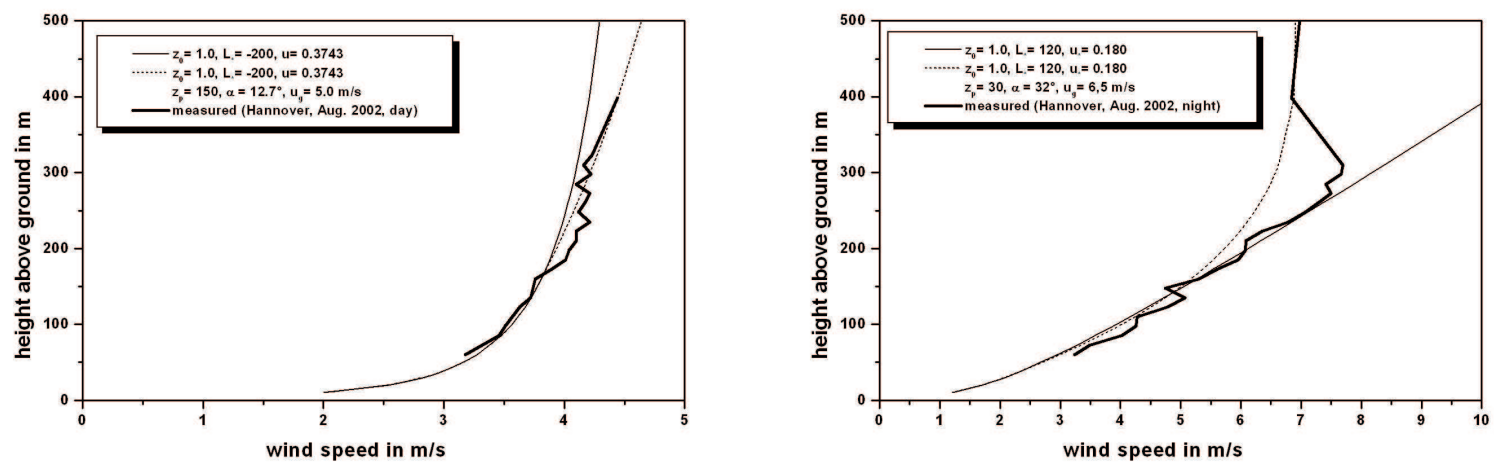

Figure 12: Comparison of analytical wind profiles to the observed mean day and night-time wind profiles in Hannover in August 2002. Bold line: observations, thin line: profile from (3.1), dotted line: profile from (3.6)
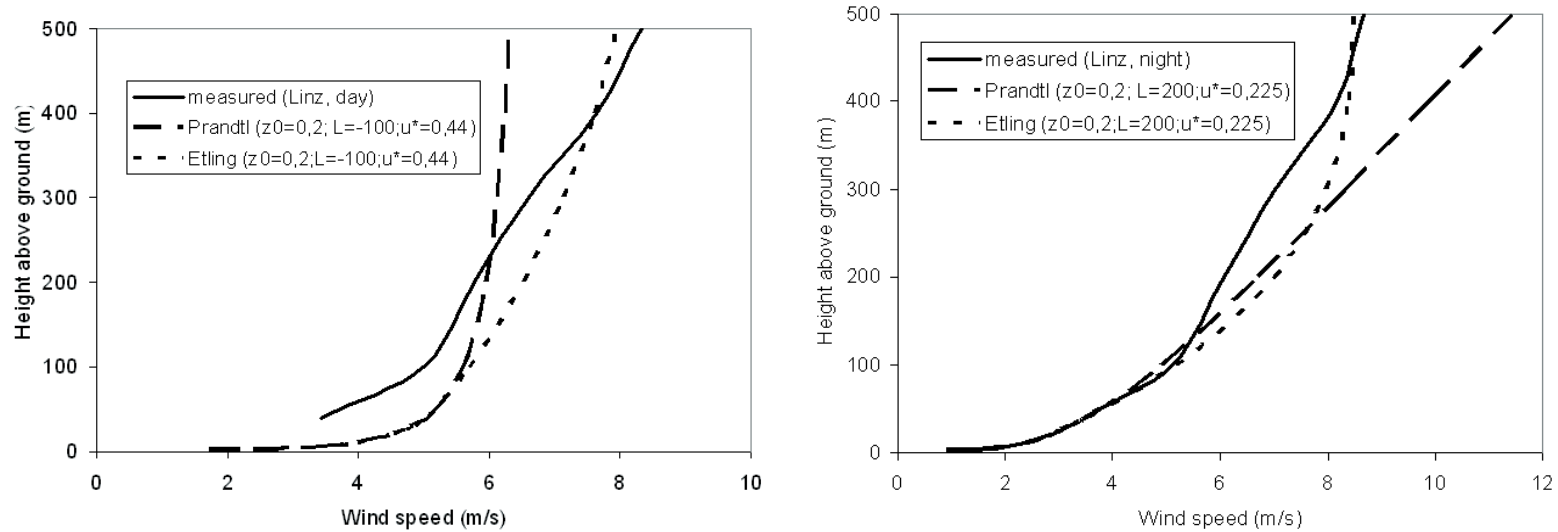

Figure 13: Comparison of analytical wind profiles to the observed mean day and night-time wind profiles in Linz in winter (November 2004 to April 2005). Bold line: observations, dashed line: profile from (3.1), dotted line: profile from (3.9).

$\sigma_{w}$ have been found to be more pronounced at the urban area (at least in spring and summer). This is due to the larger heating from surfaces in urban areas during day and night.

For Linz, a possible urban influence on the turbulence quantities can be obtained by comparing "urban" and "non-urban" wind directions. The lowest $\sigma_{w}$ values are measured with the rural easterly winds and the rare southerly winds (Fig. 10). The highest $\sigma_{w}$ values are observed for the "urban" directions west to north-west. The very high $\sigma_{w}$ values with westerly winds are caused by a combination of high wind speeds and the urban effect. The $\sigma_{w}$ values with northerly winds are close to the all data average. The $\sigma_{w}$ values under urban influence are at least twice as large as those for easterly and southerly winds with rural fetch.

Most of the mean turbulence intensity profiles for different wind directions in Linz (Fig. 11) show a decrease of turbulence with height. With northerly and southerly winds, high turbulence intensities are on average caused by the generally low wind speeds and comparably large variances. Above-average turbulence intensities are also found in Linz with the "urban" wind directions west-north-west and north-west. The lowest turbulence values are observed on average when easterly and southerly winds are prevailing. The rather small turbulence values with westerly winds are caused by the very high average wind speeds observed with this direction, thus apparently masking the influence of the urban area. The urban effect on the turbulence intensity profiles observed at Linz is over-ridden by the large differences in wind speeds associated with the different wind directions.

As expected, turbulence intensity is found to be much larger in urban areas and for profile measurements influenced by urban fetch due to larger surface roughness and larger thermal heating than at flat rural sites or under the influence of a mainly rural fetch.

\subsection{Application of analytical wind profile laws}

In Figures 1 and 3, the urban mean wind profiles in Hanover and Linz have been approximated with the Prandtl-layer wind profile from equation (3.1). But it is not meaningful to extend a Prandtl-layer profile to heights of $500 \mathrm{~m}$ and more. Even above cities this height 
is already within the Ekman layer. Thus, a profile description is needed which fulfills the requirements of both layers, the Prandtl layer and the Ekman layer, in order to adequately describe vertical wind profiles in the urban boundary layer up to several hundred metres above ground. Therefore we will examine here the twolayer model given in eq. (3.9) for Hanover and Linz in order to assess the applicability of this approach.

In Fig. 12 and 13, analytical daytime and night-time wind profiles are compared to mean wind profiles observed in Hanover in August 2002 and in Linz in winter 2004/2005. The three additional free parameters in equation (3.9) (in comparison to eq. (3.1)) are tuned in order to improve the agreement to the measured wind profiles. The first three parameters have been chosen as close as possible to the ones found in Figs. 1 and 3.

For the approximations shown in Fig. 12, the Prandtllayer height $z_{p}$ is set to $30 \mathrm{~m}$ at night and to $150 \mathrm{~m}$ at daytime. Below the height $z_{p}$ both profile laws ((3.1) and (3.9)) give identical values. The roughness length $z_{0}$ is set to $1 \mathrm{~m}$, the Monin-Obukhov length $L_{*}$ is chosen in order to represent the profile below $z_{p}$ properly, and the geostrophic wind speed is set equal to the wind speed at $500 \mathrm{~m}$. The friction velocity $u_{*}$ is then iterated from the eq. (3.11) to (3.14) as described in Chapter 3. From this iteration the friction velocity at daytime $\left(u_{*}=0.37\right.$ $\mathrm{m} / \mathrm{s}$ ) turns out to be about twice as high as at night-time $\left(u_{*}=0.18 \mathrm{~m} / \mathrm{s}\right)$. The turning angle of the wind direction changes between $32^{\circ}$ at night and $12.7^{\circ}$ at day. Both values seem reasonable.

For Linz (Fig. 13), the Prandtl-layer height $z_{p}$ is set to $30 \mathrm{~m}$ at night and to $60 \mathrm{~m}$ at daytime. With these values, the profiles from (3.9) show the best fit to the wind data in upper levels. The daytime value for $z_{p}$ is much lower than that used for Hanover which can be explained by the predominantly wintertime data set at Linz compared to the August data from Hanover. The roughness length at Linz is $0.2 \mathrm{~m}$, the Monin-Obukhov length $L_{*}$ is derived from ultrasonic anemometer measurements to be $-100 \mathrm{~m}$ on average during daytime and $200 \mathrm{~m}$ during night. As in Hanover, the geostrophic wind speed is set equal to the wind speed at $500 \mathrm{~m}$, and the friction velocity, again determined iteratively, is also about twice as large during daytime $(0.44 \mathrm{~m} / \mathrm{s})$ than during night $(0.225$ $\mathrm{m} / \mathrm{s})$. The turning angle of the wind direction changes between $28^{\circ}$ at night and $17^{\circ}$ during daytime.

\section{Discussion}

The average wind speed, the standard deviation of the vertical velocity and turbulence intensity profiles observed in three cities of different size, Moscow, Hanover and Linz show similarities as well as differences: daytime wind speeds are on average higher than nighttime wind speeds at higher levels in spring (Hanover,
Moscow) and summer (Moscow) and lower than the nocturnal wind speeds throughout the lowest few hundred meters in autumn and winter in all three cities. As expected, daytime wind speed profiles tend to be less stable than night-time profiles. This is most pronounced in spring and summer. The wind speed profiles of the largest city, Moscow, show the weakest increase of wind speed with height and thus the strongest urban impact on stability. In winter differences between day and night are small in all three cities as the stratification of the air is always quite stable.

In Linz, westerly to north-westerly winds cross the city before reaching the SODAR site, while the wind profiles observed by the SODAR with other wind directions are affected by hilly or rural terrain. Wind speeds are increasing with height up to $500 \mathrm{~m}$ above ground in all mean wind profiles; this increase of wind speed is in most cases less pronounced above $400 \mathrm{~m}$. Urban effects on the wind speed profiles at Linz are seen in an aboveaverage increase in wind speed with height at low levels as well as in a wind speed maximum at $100 \mathrm{~m}$ when the flow crosses the urban area before reaching the SODAR site. The latter is interpreted as an urban effect in this case, because the increased vertical mixing over the city increases instability and thus accelerates the flow.

The following main part of this discussion will be focused on two issues: the increase of $\sigma_{w}$ with height and the description of the whole vertical wind profile by the two-layer model (3.9).

The $\sigma_{w}$ profiles observed in Hanover and Linz are of the same magnitude and in general increase with height, especially in spring and summer. The reasons for this increase are probably twofold. The first reason is that in the lower one hundred metres above the town the nocturnal thermal stratification remains slightly unstable in spring and summer. This can e.g. be inferred for Hanover from some days for which additionally temperature profiles from a RASS (Radio acoustic sounding system) measurement had been available (EMEIS et al., 2004). In Figs. 5 to 7 in EMEIS et al. (2004) it is shown for three days in spring 2002 that the temperature at roof-top level (43 $\mathrm{m}$ above ground) is more than $1{ }^{\circ} \mathrm{C}$ larger than at about $100 \mathrm{~m}$ above ground at night. Above this unstable layer the RASS data show that the atmosphere is stably stratified up to about $400 \mathrm{~m}$ as has already been inferred from the wind profiles shown in Figs. 1 and 3. The second reason for the increase of $\sigma_{w}$ with height is the frequent formation of low-level jets at the top of the nocturnal stable layer at about $400 \mathrm{~m}$ above ground in spring and summer as is also to be seen from the upper right and lower left frames in Figure 1. These low-level jets lead to a mechanical production of turbulence at night in heights between $100 \mathrm{~m}$ and $400 \mathrm{~m}$ above ground, a fact which had already been proven in Reitebuch et al. (2000). 
Additionally the $\sigma_{w}$ profiles observed on average in February in Hanover as well as those measured during wintertime in Linz are highly dependent on the wind direction: the largest values of $\sigma_{w}$ occur with strong westerly winds. Day-night differences are large in both cities, up to a factor of two in Linz. The $\sigma_{w}$ values measured in Linz when the "urban" wind directions west to northwest are prevailing are considerably larger than for the more rural easterly and southerly winds. The nocturnal $\sigma_{w}$ values over Hanover, Moscow, and Linz are considerably larger than over rural areas (see also EMEIS (2004)). This is in agreement with the findings presented by UNO et al. $(1988,1992)$ and DUPONT et al. (1999) who also showed that the large roughness of the town surface and the urban heat island prevents the formation of a cool stably stratified nocturnal surface layer as it is typical for rural areas for nights with clear skies. Further, the near-surface values of the variances $\sigma_{w}$ over the larger cities Hanover and Moscow are larger than could be expected from the friction velocity using (3.3) and (3.5). This hints to the fact that turbulence production over rough surfaces with bluff bodies is larger than over flat surfaces with the same roughness length and friction velocity. Similar enhancements of turbulence have been found over forests (HÖGSTRÖM et al., 1989).

Fewer similarities are found between the average turbulence intensity profiles in Hanover and Linz. The February profiles in Hanover show a sharp decrease with height in the lowest 150 to $200 \mathrm{~m}$. The Linz profiles reveal a much weaker decrease and a stronger dependence on the wind direction. Conceptually, turbulence intensity in urban areas or in hilly terrain is expected to be higher than in rural areas. In Linz, the results on turbulence intensity are influenced by the large directional differences in wind speed: although west-northwesterly, north-westerly winds and in general daytime profiles show higher turbulence intensities, the largest values occur with southerly and northerly winds, which have by far the lowest average wind speeds. So the possible urban effect on the turbulence intensity in Linz is masked by the significant differences in wind speed of different regional flow directions and by orographic effects.

Because the division between the Prandtl layer and the Ekman layer is not very clear over urban areas due to the larger turbulence also several hundreds of metres above ground a unified description of the vertical wind profile for the whole boundary layer over these areas is desirable. From the results presented in this paper the amended Etling approach (3.9) for the combined analytical description of wind profiles in the Prandtl and Ekman layer seems to be a reasonable tool to approximate the measured urban wind profiles. Figs. 12 and 13 show that in the cases analysed here the modified Etling approach (3.9) leads to smaller wind speed values at greater heights at night-time but to higher wind speeds at these heights during day-time compared to the pure logarithmic profiles from equ. (3.1). Both times equation (3.9) fits the observational data better than equation (3.1). Especially at night time we see that the profiles are reproduced rather well with the sole exception of the low-level jet in Hanover. As the equations (3.9) and (3.1) are derived for stationary conditions, an unstationary feature like a low-level jet can not be reproduced by these analytical profiles. The approximation of the wind profile using the Etling approach works well in both cities with their different environments and having used data from different seasons.

This success of the two-layer model (3.9) is not too much surprising because this approach depends on six variables which need to be chosen and which can be tuned according to the measurements in the presented cases. In doing this tuning it turns out that the right choice of the Prandtl-layer height $z_{p}$ in the two-layer model (3.9) is the most important task. If $z_{p}$ is not chosen appropriately then no combination of the other five parameters will lead to a satisfying fit of the wind profile. The extension of the original version of this approach (ETLING, 2002) by adding the correction terms for nonneutral stratification for heights below the Prandtl layer height as described in Section 3 enhanced the applicability of this approach and led to much more meaningful values of $z_{p}$.

\section{Conclusions}

In this paper, mean SODAR measurements of urban wind and turbulence profiles in three differently sized cities are presented. Although they show common and consistent features, they allow only a qualitative estimation of the urban influence. Having used data from three cities with roughly $200,000,500,000$ and $10,000,000$ inhabitants, it is not justified to derive quantitative dependencies on features like size and population characterising a city. Typical urban features are a higher wind shear in heights of several hundreds of meters above ground, a larger increase of $\sigma_{w}$ with height especially at night, and a doubling of the turbulence intensity. The nocturnal increase of $\sigma_{w}$ with height in spring and summer is not just an urban feature but a feature which comes from the interaction between rural and urban air flows. Lowlevel jets form over rural areas and the additional surface friction due to cities is not sufficient to destroy them. Thus, the higher mechanically-produced turbulence below low-level jets in heights between 100 and $400 \mathrm{~m}$ above ground continues the higher thermally-produced turbulence in the urban boundary layer below $100 \mathrm{~m}$. The results of this study have shown that urban areas and forests have mechanically some features in common 
(enhanced turbulence intensity). Looking at thermal features they are very different as forests exhibit no features that are comparable to the urban heat island.

The knowledge of these urban features and the improved analytical description of the urban wind profile up to $500 \mathrm{~m}$ which is proposed in this paper help with the assessment of the conditions for pollutant transport over heavily populated areas. Urban areas are known for their strong emissions of pollutants, and reliable dispersion calculations are a mandatory prerequisite for air pollution mitigation strategies. Likewise, the information on urban wind and turbulence profiles is valuable to test and validate meso-scale and micro-scale numerical flow simulation models. As the population living in cities is still growing, these models are indispensable for air quality forecasts as well as for studies concerning the impact of climate change on the health prospects for large parts of the Earth's population.

\section{References}

ARYA, S.P., 1995: Atmospheric boundary layer and its parameterization. - In: CERMAK, J.E. et al. (Hrsg.): Wind Climate in Cities. Kluwer, Dordrecht, 41-66.

BALling, R. C. JR., R.S. CERVENY,, 1987: Long-term association between wind speeds and the urban heat island of Phoenix, Arizona. - J. Climate Appl. Meteor. 26, 712-716.

Batchvarova, E., S.-E. Gryning, 2006: Progress in urban dispersion studies. - Theor. Appl. Climatol. 84, 57-67.

BEYRICH, F., 1997: Mixing height estimation from sodar data - a critical discussion. - Atmos. Environ. 31, 39413953.

Businger, J.A., J.C. WYNGAARD, Y. IZUMi, E.F. BRADLEY, 1971: Flux profile relationships in the atmospheric surface layer. - J. Atmos. 28, 181-189.

CAsadio, S., A. Di SARra, G. Fiocco, D. Fua, F. Lena, M.P. RAO, 1996: Convective characteristics of the nocturnal urban boundary layer as observed with Doppler sodar and Raman lidar. - Bound.-Layer Meteor. 79, 375-391.

CERC, 2001: Cambridge Environmental Research Consultants, ADMS dispersion model. - http://www.cerc.co.uk.

Counihan, J., 1973: Simulation of an adiabatic urban boundary layer in a wind tunnel. - Atmos. Environ. 7, 673689.

Dobre, A., S.J. ARnold, R.J. Smalley, J.W.D. Boddy, J.F. BARlow, A.S. TOMlin, S.E. Belcher, 2005: Flow field measurements in the proximity of an urban intersection in London, UK. - Atmos. Environ. 39, 4647-4657.

DRAXLER, R. R., 1986: Simulated and observed influence of the nocturnal urban heat island on the local wind field. - J. Climat. Appl. Meteor. 25, 1125-1133.

Dupont, E., L. Menut, B. Carissimo, J. Pelon, P. Flamant, 1999: Comparison between the atmospheric boundary layer in Paris and its rural suburbs during the ECLAP experiment. - Atmos. Environ. 33, 979-994.

Dupont, S., P. G. Mestayer, 2006: Parameterisation of the urban energy budget with the submesoscale soil model SM2-U. - J. Appl. Meteor. Climatol. 45, 1744-1765.
DYER, A.J., 1974: A review of flux-profile relations. Bound.-Layer Meteor. 1, 363-372.

EMEIS, S., 2001: Vertical variation of frequency distributions of wind speed in and above the surface layer observed by sodar. - Meteorol. Z. 10, 141-149.

-, 2004: Vertical wind profiles over an urban area. - Meteorol. Z. 13, 353-359.

EMEIS, S., M. TÜRK, 2004: Frequency distributions of the mixing height over an urban area from SODAR data. - Meteorol. Z. 13, 361-367.

Emeis, S., C. Münkel, S. Vogt, W.J. Müller, K. SCHÄFER, 2004: Atmospheric boundary-layer structure from simultaneous SODAR, RASS, and ceilometer measurements. - Atmos. Environ. 38, 273-286.

Etling, D., 2002: Theoretische Meteorologie Eine Einführung. 2. Auflage. - Springer-Verlag, Berlin, Heidelberg, New York, 354 pp.

FARELL, C., A.K.S. IYENGAR, 1999: Experiments on the wind tunnel simulation of atmospheric boundary layers. J. Wind Eng. Indust. Aerodyn. 79, 11-35.

Fisher, B., S. Joffre, J. KuKKonen, M. Piringer, M. Rotach, M. Schatzmann (Eds.), 2005: Meteorology applied to urban air pollution problems. - Final Report of COST Action 715. ISBN 954-9526-30-5., Demetra Ltd. Publishers. Printed in Bulgaria, 276 pp.

GRIMMOND, C.S.B., 2006: Progress in measuring and observing the urban atmosphere. - Theor. Appl. Climatol. 84, 3-22.

Hildebrand, P.H., B. ACKERMAnN, 1984: Urban Effects on the Convective Boundary Layer. - J. Atmos. Sci. 41, 7691.

HöGströM, U., 1988: Non-dimensional wind and temperature profiles in the atmospheric surface layer: a reevaluation. - Bound.-Layer Meteor. 42, 55-78.

Högström, U., H. Bergström, A.-S. Smedman, S. HALldin, A. LindRoth, 1989: Turbulent exchange above a pine forest, I: Fluxes and gradients. - Bound.-Layer Meteor. 49, 197-217.

LAnge, M., U. Focken, 2006: Physical Approach to ShortTerm Wind Power Prediction. - Springer, Berlin Heidelberg, 208 pp.

Lokoshchenko, M.A., 2002: Long-Term Sodar Observations in Moscow and a New Approach to Potential Mixing Determination by Radiosonde Data. - J. Atmos. Oceanic Technol. 19, 1151-1162.

Martilli, A., A. Clappier, M. W. Rotach, 2002: An urban surface exchange parameterisation for mesoscale models. - Bound.-Layer Meteor. 104, 261-304.

MAsson, V., 2000: A physically-based scheme for the urban energy budget in atmospheric models. - Bound.-Layer Meteor. 94, 357-397.

Maughan, R.A., A.M. Spanton,D M.L. Williams, 1982: An analysis of the frequency distribution of SODAR derived mixing heights classified by atmospheric stability. - Atmos. Environ. 16, 1209-1218.

Melling, H., R. List, 1980: Characteristics of Vertical Velocity Fluctuations in a Convective Urban Boundary Layer. - J. Appl. Meteor. 19, 1184-1195.

Panofsky, H.A., H. TenneKeS, D.H. Lenschow, J.C. WYNGAARD, 1977: The characteristics of turbulent velocity components in the surface layer under convective conditions. - Bound.-Layer Meteor. 11, 355-361. 
Pekour M.S., M.A. Kallistratova, 1993: Sodar study of the boundary layer over Moscow for air pollution application. - Appl. Phys. B 57, 49-55.

PeKour M.S., M.A. Kallistratova, M.A. LokoshCHenko, I.V. PETEnKo, 1993: Acoustic sounding study of the mixing layer over a city. - In: Optical monitoring of the environment, Proceedings of SPIE, Vol. 2107, SPIE, Bellingham, WA, 1993, 169-193.

Piringer, M., K. BAUMAnN, 1999: Modifications of a valley wind system by an urban area - experimental results. Meteor. Atmos. Phys. 71, 117-125.

PIRINGER, M., S. JOFFre (Eds.), 2005: The urban surface energy budget and mixing height in European cities: data, models and challenges for urban meteorology and air quality. - Final report of Working Group 2 of COST Action 715. ISBN 954-9526-29-1, Demetra Ltd. Publishers. Printed in Bulgaria, $239 \mathrm{pp}$.

Piringer, M., S. Joffre, A. BAKLANOV, A. ChrisTEN, M. Deserti, K. DE Ridder, S. Emeis, P. MesTAYER, M. TOMBrou, D. Middleton, K. BAUMANNStAnzer, A. DANDou, A. KARPpinen, J. BuRZYNSKi, 2007: The surface energy balance and the mixing height in urban areas - activities and recommendations of COSTAction 715. Published online April 5, 2007 in Bound.Layer. Meteor. DOI: 10.1007/s10546-007-9170-0.

Plate, E.J., 1995: Urban Climates and Urban Climate Modelling: An Introduction. - In: CERMAK, J.E. et al. (Eds.:) Wind Climate in Cities. NATA ASI Series E277, Kluwer Acad. Publ., Dordrecht, 23-39.

ReITEBuCH, O., S. EMEIS, 1998: SODAR-measurements for atmospheric research and environmental monitoring. Meteorol. Z., N. F. 7, 11-14.

Reitebuch, O., A. Strassburger, S. Emeis, W. KutTLER, 2000: Nocturnal secondary ozone concentration maxima analysed by sodar observations and surface measurements. - Atmos. Environ. 34, 4315-4329.

RotACH, M.W., 1999: On the influence of the urban roughness sublayer on Turbulence and dispersion. - Atmos. Environ. 33, 4001-4008.

Rotach, M.W., R. Vogt, C. Bernhofer, E. BAtCHvarova, A. Christen, A. Clappier, B. Feddersen,
S.-E. Gryning, G. Martucci, H. Mayer, V. Mitev, T. R. OKe, E. PARlow, H. Richner, M. Roth, Y.-A. Roulet, D. RuffieuX, J. A. SAlmond, M. SchatzMANN, J. A. Voogt, 2005: BUBBLE - an Urban Boundary Layer Meteorology Project. - Theor. Appl. Climatol. 81, 231-261.

Roth, M., 2000: Review of atmospheric turbulence over cities. - Quart. J. Roy. Meteor. Soc. 126, 941-990.

RoTH, M., T.R. OKE, 1995: Relative efficiencies of turbulent transfer of heat, mass, and momentum over a patchy urban surface. - J. Atmos. Sci. 52, 1863-1874.

Schatzmann, M., B. Leith, 2002: Validation and application of obstacle-resolving urban dispersion models. - Atmos. Environ. 36, 4811-4821.

SCHATZMANN, M., W. BÄChlin, S. EMEIS, J. Kühlwein, B. Leitl, W.J. MÜller, K. SCHÄFER, H. SCHLÜNZEN, 2006: Development and Validation of Tools for the Implementation of European Air Quality Policy in Germany (Project VALIUM). - Atmos. Chem. Phys. 6, 3077-3083.

Stull, R.B., 1988: An Introduction to Boundary Layer Meteorology. - Kluwer Acad. Publ., 666 pp.

TATARSKII, V.I., 1961: Wave Propagation in a Turbulent Medium. Translated from Russian by R. A. Silverman. McGraw-Hill, New York, 285 pp.

Uno, I., S. Wakamatsu, H. Ueda, A. Nakamura, 1988: An observational study of the structure of the nocturnal urban boundary layer. - Bound.-Layer Meteor. 45, 59-82.

,,,,---- 1992 : Observed structure of the nocturnal urban boundary layer and its evolution into a convective mixed layer. - Atmos. Environ. 26B, 45-57.

Venkatramm, A., V. IsAKov, D. PANKRATZ, J. HEUMANN, J. YUAN, 2004: The analysis of data from an urban dispersion experiment. - Atmos. Environ. 38, 36473659.

WIERINGA, J., 1973: Gust factors over open water and builtup country. - Bound.-Layer Meteor. 3, 424-441.

—, 1993: Representative roughness parameters for homogeneous terrain. - Bound.-Layer Meteor. 63, 323-363. 